\title{
PENGEMBANGAN ALAT BANTU LATIHAN UNTUK PROSES REHABILITASI BAGI PASIEN PASCA STROKE
}

\author{
Titiek Koesdijati' ${ }^{1)}$, M. Nushron Ali $\mathbf{M}^{2)}$ \\ ${ }^{1}$ Fakulltas Teknologi Industri, Universitas PGRI Adi Buana Surabaya \\ email : Titik@unipasby.ac.id \\ ${ }^{2}$ Fakulltas Teknologi Industri, Universitas PGRI Adi Buana Surabaya \\ email: Nushron@unipasby.ac.id
}

\begin{abstract}
Stroke is a disease that is still considered terrible at this time, the cause is none other than due to lifestyle and unhealthy diet. It is this condition that causes post-stroke patients can not freely engage, therefore a therapeutic device design is needed so that patients can be cured of paralysis immediately. The design process using QFD method so that the needs and designs are expected to be in accordance with the wishes of the patient. Anthropometry is used to determine the size of the patient's palm. The eco design method is used in the selection of materials to be used to support the creation of green production. The results of anthropometric data measurement for the 5th percentile are at Ptm $=73.26 \mathrm{~mm}$, Dgmak $=20.85 \mathrm{~mm}, \mathrm{Ttm}=16.98$, while for the 95th percentile in the Ltm $=$ 92.32, Dgmin $=14.09$, Lkt $=102.78$ and $T g k t=63.93$. Test data reliability shows that the adjustability aspect has the highest value of 0.9156, then ranks both finishing aspects with the value of 0.867 and the last is the material aspect with the value 0.7562. Based on the overall attribute used as instrumentation, which is a number of 13 attributes. The highest rating is on the easy attribute in the assembly.
\end{abstract}

Keyword: Rehabilitation, Stroke, Ergonomic, QFD

\section{PENDAHULUAN}

Angka kematian karena stroke sampai saat ini masih tinggi. Berdasarkan data yang dihimpun oleh World Health Organisation (WHO), pada tahun 2008 ada sekitar 6,2 juta kematian karena yang disebabkan oleh stroke (WHO, 2012) dan merupakan penyebab kematian no 3 di dunia setelah jantung koroner dan kanker (WHO, 2007). Di Indonesia sendiri, stroke merupakan penyebab utama kematian dengan prevalensi berdasarkan Riset Kesehatan Dasar (Riskesdas) tahun 2007 adalah 8 kasus per 1000 jiwa (Sedyaningsih, 2011). Pada umumnya penderita stroke akan menjadi bergantung pada bantuan orang lain dalam menjalankan aktivitas kehidupannya sehari -hari (activities of daily living/ADL) seperti makan dan minum, mandi, berpakaian dan sebagainya. Kemandirian dan mobilitas seseorang yang menderita stroke men jadi berkurang atau bahkan hilang. Serangan stroke yang dialami dapat membawa kelainan neurologis seperti berkurangnya kemampuan motorik anggota tubuh dan otot, kognitif, visual dan koordinasi secara signifikan.

Dalam pelayanan rehabilitasi ini merupakan pelayanan dengan pendekatan multidisiplin yang terdiri dari dokter ahli syaraf, dokter rehabilitasi medik, perawat, fisioterapis, terapi occupational, pekerja sosial medik, psikolog serta klien dan keluarga turut berperan. Mobilisasi merupakan salah satu bentuk rehabilitasi awal dari kondisi penyakit tertentu, dalam hal ini pada klien yang mengalami serangan stroke sehingga terhindar dari komplikasi.

Terdapat peningkatan jumlah pasien yang memerlukan perawatan jangka panjang untuk memperbaiki kerusakan saraf yang dialami pasien. Pedoman Sistem Kesehatan Nasional telah merekomendasikan pengurangan lama rawat inap, karena kurangnya fasilitas rehabilitatif yang tersedia dan kebutuhan untuk mencapai penghematan biaya operasional (Burdea, G, 2000). Hal ini juga menunjukkan bahwa dengan pemulangan dini, ditambah dengan pelaksanaan terapi di rumah sendiri dapat 
bermanfaat bagi pasien pasca stroke dalam meningkatkan kualitas hidup pasien.

Johanna dalam penelitiannya telah mengidentifikasi beberapa persyaratan untuk kebutuhan proses rehabilitasi pasien pasca stroke, diantarannya terapi dilakukan di rumah, waktu terapi yang fleksibel, terapi yang mandiri, sistem dapat memberikan contoh aktivitas yang akan dilakukan saat terapi, sistem terapi yang aman.( Johanna,2013)

Proses desain dari suatu produk yang akan diproduksi harus dapat memenuhi beberapa aspek, terutama jika produk tersebut akan digunakan untuk keperluan manusia. Diantaranya seperti aspek ergonomi, aspek raw material, aspek keamanan dan juga aspek lingkungan. Aspek lingkungan sangat penting dalam menghasilkan produk yang ramah lingkungan, dalam artian produk tersebut dapat didesain sedemikian rupa mulai dari raw material hingga purna pakai, barang yang dibuat dapat digunakan lagi/reuse maupun didaur ulang/recycle. Sehingga dapat menghasikan produk yang bermanfaat tidak hanya bagi manusia namun juga bagi lingkungan sekitar serta mendukung aktivitas yang mengarah pada green production.

Berdasarkan uraian diatas maka dalam penelitian ini akan mengembangkan alat bantu terapi untuk proses rehabilitasi bagi pasien pasca stroke, yang untuk terapi kaki akan dikembangkan dengan alat terapi dengan menggunakan tangan. Proses pengukuran dimensi beberapa komponen yang berkaitan langsung dengan anggota tubuh terutama bagian tangan, akan dianalisis menggunakan anropometri, terutama pada bagian tangan dan kaki. Hal ini dapat memberikan rangsangan agar dapat beraktifitas layaknya manusia normal, bagian tangan dan kaki harus lebih sering diterapi untuk mempercepat proses rehabilitasi. Sedangkan dalam penyesuaian terhadap keinginan pasien, maka dalam penelitian ini akan diidentifikasi beberapa atribut-atribut yang berguna dalam pembuatan rancangan dengan menggunkan metode QFD (Quality Function Deployment).

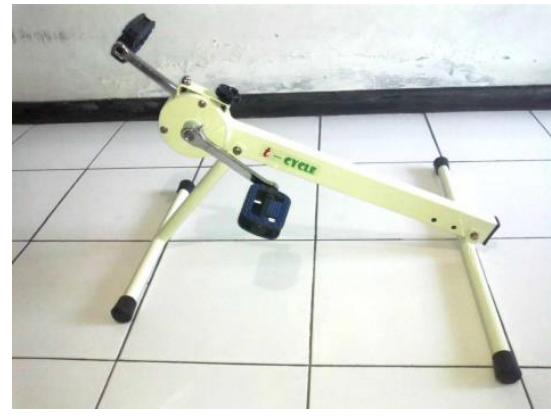

Gambar 2.6 sepeda statis portable

Jenis sepeda statis diatas dapat dipindah dengan mudah jika tidak digunakan, atau dengan kata lain mudah dalam penyimpanan, bentuknyapun sederhana dan ringan. Akan tetapi bagian tubuh yang dapat diterapi hanya kaki saja, sedangkan untuk bagian tangan tidak dapat di terapi

Oleh karenanya jenis alat akan dikembangkan dalam penelitian ini adalah seperti pada gambar $2.3 \mathrm{c}$ yaitu steady cycle atau sepeda diam. Jika dilihan dengan seksama alat tersebut hanya digunakan untuk melatih anggota tubuh bagian kaki saja, namun tidak diperuntukkan untuk anngota tubuh yang lainnya seperti tangan. Oleh karenannya perlu ada perbaikan dan pengembangan alat agar dapat digunakan untuk melatih angota tubuh bagian kaki dan tangan, sehingga proses rehabilitasi untuk beberapa anggota tubuh dapat dilakukan sekaligus dengan hanya amenggunakan satu alat

\section{METODE PENELITIAN}

Penentuan bobot kepentingan desain perancangan metode yang digunakan adalah QFD dalam mencari atribut produk untuk membobotkan atribut berdasarkan keinginan konsumen. Untuk keefektifan penelitian maka peneliti bekerjasama dengan pihak dokter specialis syaraf rumah sakit daerah, untuk menghimpun informasi yang dibutuhkan mengenai kemungkinan jika alat diterapkan pada pasien pasca stroke. Serta beberapa pasien pasca stroke yang dalam hal ini untuk mengetahui kriteria alat yang sesuai dengan kebutuhan untuk proses reahbilitasi.

Proses identifikasi dilakukan ketika posisi tangan pada saat menggengam suatu alat. Sehingga tidak semua data untuk antropomeri tangan seperti yang tersebut pada tabel 2.1 akan diukur pada penelitian ini. Berikut data 
pengambilan data antropometri yang akan dilakukan.

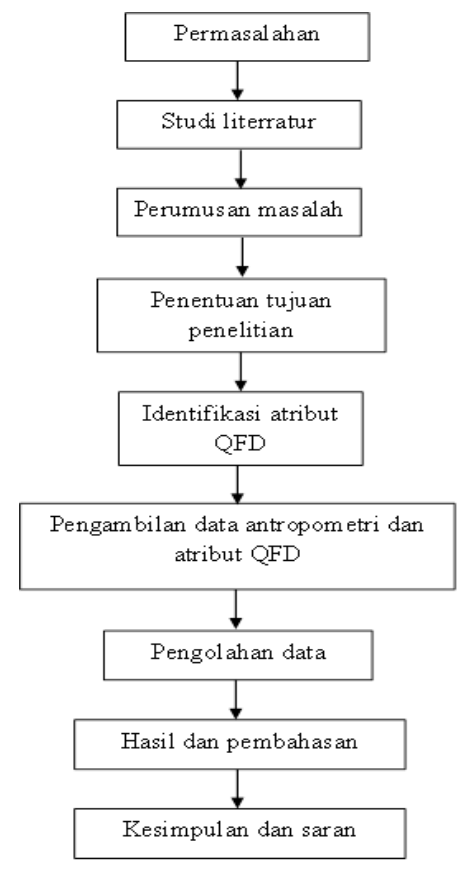

Gambar 2. Flow chart penelitian

Pengumpulan data dilakukan dengan cara primer dan sekunder. Data primer diperoleh dari hasil pengambilan data antrpometri dengan cara mengukur anggota tubuh seseorang dengan alat ukur. Data sekunder menggunakan data literatur dari jurnal dan literatur lainnya serta hasil konsultasi dengan beberapa dokter spesialis syaraf pada rumah sakit daerah. Data yang diperlukan untuk membuat HOQ:

1. Identifikasi flesibilitas penggunaan alat dalam proses penggunaan.
2. Identifikasi kebutuhan teknis berdasarkan dimensi peralatan yang akan dibuat.

3. Menentukan hubungan antara kebutuhan pasien dengan kebutuhan teknis

4. Melakukan penilaian pada keinginan pengguna dengan kebutuhan teknis.

Hasil dari pengambilan data antropometri selanjutnya di hitung rata-rata dan standart deviasi menggunakan persaman 2.1 dan 2.2. berdasarkan data antropometri tersebutselanjutnya akan digunakan sebagai acuan dalam mendesain peralatan yang akan dibuat.

\section{HASIL DAN PEMBAHASAN}

Data antropometri diperoleh berdasarkan hasil sebaran quisioner yang diberikan kepada semua responden yang berjumlah 30 orang yang sedang menjalani rehabilitasi pasca stroke. Tempat atau lokasi pengambilan bermacam-macam. Namun data terbanyak diperoleh dari beberapa rumah sakit/klinik yang menyediakan rehabilitasi pasca stroke. Seperti di RS Husada Utama Surabaya dan bhakti luhur sidoarjo. Data antropometri adalah sebagai berikut.:

Tabel 1. data hasil pengukuran antropometri tangan

\begin{tabular}{c|c|c|c|c|c|c|c}
\hline & \multicolumn{6}{|c}{ DATA HASIL PENGUKURAN ANTROPOMETRI } \\
$\mathbf{n}$ & Ptm & Ltm & Dgmak & Dgmin & Lkt & Tgkt & Ttm \\
\hline 1 & 85 & 78 & 35 & 12 & 95 & 62 & 21 \\
2 & 74 & 93 & 37 & 15 & 100 & 61 & 22 \\
3 & 78 & 8 & 26 & 10 & 91 & 54 & 25 \\
4 & 90 & 83 & 29 & 12 & 98 & 48 & 27 \\
5 & 83 & 93 & 32 & 13 & 105 & 47 & 29 \\
6 & 90 & 83 & 30 & 8 & 91 & 55 & 30 \\
7 & 83 & 78 & 28 & 10 & 89 & 58 & 24 \\
8 & 78 & 93 & 29 & 10 & 97 & 60 & 21 \\
9 & 85 & 72 & 33 & 15 & 99 & 58 & 27 \\
10 & 72 & 85 & 34 & 10 & 90 & 56 & 22 \\
11 & 84 & 8 & 30 & 12 & 103 & 51 & 23 \\
\hline
\end{tabular}




\begin{tabular}{c|c|c|c|c|c|c|c}
\hline 12 & 83 & 84 & 29 & 11 & 97 & 49 & 26 \\
13 & 80 & 84 & 26 & 8 & 98 & 59 & 21 \\
14 & 84 & 82 & 26 & 12 & 89 & 57 & 22 \\
15 & 78 & 8 & 30 & 10 & 93 & 53 & 29 \\
16 & 72 & 82 & 26 & 10 & 96 & 62 & 23 \\
17 & 80 & 82 & 29 & 13 & 94 & 58 & 21 \\
18 & 75 & 78 & 32 & 9 & 90 & 56 & 26 \\
19 & 78 & 82 & 26 & 10 & 102 & 59 & 28 \\
20 & 82 & 93 & 32 & 11 & 92 & 48 & 24 \\
21 & 84 & 8 & 30 & 9 & 89 & 61 & 23 \\
22 & 80 & 72 & 32 & 12 & 89 & 46 & 21 \\
23 & 78 & 85 & 28 & 14 & 94 & 57 & 24 \\
24 & 81 & 84 & 30 & 12 & 102 & 54 & 28 \\
25 & 83 & 84 & 32 & 10 & 98 & 59 & 25 \\
26 & 87 & 84 & 28 & 11 & 93 & 60 & 29 \\
27 & 93 & 83 & 29 & 10 & 92 & 62 & 26 \\
28 & 84 & 84 & 32 & 9 & 99 & 61 & 25 \\
29 & 78 & 93 & 28 & 11 & 97 & 57 & 24 \\
30 & 83 & 78 & 28 & 13 & 90 & 54 & 25 \\
SUM & 2445 & 2204 & 896 & 332 & 2852 & 1682 & 741 \\
AVV & 81.5 & 73.5 & 29.9 & 11.1 & 95.1 & 56.1 & 24.7 \\
\hline
\end{tabular}

Dari data pada tabel 1 selanjutnya diolah untuk dapat diketahui standar deviasi untuk setiap atribut antropometri. Data dapat dilihat pada tabel 2 .

Tabel 2 hasil perhitungan standart deviasi

\begin{tabular}{c|c|c|c|c|c|c|c}
\hline \multirow{2}{*}{$\mathbf{n}$} & \multicolumn{7}{|c}{ Varians dan Standart Deviasi } \\
\cline { 2 - 8 } & Ptm & Ltm & Dgmak & Dgmin & Lkt & Tgkt & Ttm \\
\hline var & 25.09 & 30.08 & 7.84 & 3.37 & 22.00 & 22.82 & 7.67 \\
SD & 5.01 & 5.48 & 2.80 & 1.84 & 4.69 & 4.78 & 2.77 \\
\hline
\end{tabular}

Dalam penentuan persentile terdapat dua jenis yang digunakan, yaitu persentile 5 dan persentile 95. Hasil dari perhitungan persentile seperti pada Tabel 3

Tabel 3 tabel hasil perhitungan persentile

\begin{tabular}{c|c|c|c|c|c|c}
\hline \multicolumn{3}{c|}{ Persentile 5th } & \multicolumn{4}{c}{ Persentile 95th } \\
\hline Ptm & Dgmak & Ttm & Ltm & Dgmin & Lkt & Tgkt \\
73.26 & 20.85 & 16.98 & 92.32 & 14.09 & 102.78 & 63.93 \\
\hline
\end{tabular}

\section{Analisis QFD}

Data quisioner yang telah diperoleh kemudian diolah untuk menguji tingkat
Validitas Kuisioner dan Tingkat Kepentingan atribut.

a. Uji Validitas 
Tabel 4 Hasil uji Validitas Atribut QFD

\begin{tabular}{|c|c|c|c|}
\hline No & Keterangan & $\begin{array}{c}\text { Koefisien } \\
\text { Korelasi }\end{array}$ & Status \\
\hline A & Aspek Bahan & & \\
\hline 1 & $\begin{array}{l}\text { Bahan terbuat dari material yang ringan namun } \\
\text { kuat }\end{array}$ & 0.756 & Valid \\
\hline 2 & Bahan untuk pedal dan pegangan tangan tidak keras & 0.856 & Valid \\
\hline 3 & Alat tidak mudah bergeser pada saat digunakan & 0.768 & Valid \\
\hline 4 & Bahan tidak mudah karat & 0.906 & Valid \\
\hline B & Aspek adjustability & & \\
\hline 1 & Alat dapat diatur/disesuaikan panjang pendeknya & 0.934 & Valid \\
\hline 2 & Putaran engkolan dapat diatur (ringan -berat) & 0.908 & Valid \\
\hline 3 & $\begin{array}{l}\text { Putaran engkol dapat digunakan untuk tangan dan } \\
\text { kaki }\end{array}$ & 0.965 & Valid \\
\hline 4 & $\begin{array}{l}\text { Pada penggunaan untuk tangan dapat diatur } \\
\text { panjang pendeknya jangkauan }\end{array}$ & 0.863 & Valid \\
\hline 5 & $\begin{array}{l}\text { Alat dapat dilipat jika dan mudah dalam } \\
\text { penyimpanan }\end{array}$ & 0.682 & Valid \\
\hline 6 & Mudah dalam perakitan & 0.867 & Valid \\
\hline C & Aspek finishing & & \\
\hline 1 & Cat/pelapis tidak mudah luntur & 0.768 & Valid \\
\hline 2 & Tidak mudah terkelupas & 0.895 & Valid \\
\hline 3 & Warna menarik & 0.917 & Valid \\
\hline
\end{tabular}

Berdasarkan data pada Tabel 4 diatas dapat diketahui bahwa semua item pertanyaan telah memenuhi kriteria validitas. Koefisien korelasi tingkat kepentingan berkisar antara 0.682-0.965. Sehingga dari 13 item pertanyaan untuk tingkat kepentingan dinyatakan valid.

b. Uji Reabilitas
Uji reabilitas dilakukan dengan tujuan untuk mengetahui sejauh mana hasil dari suatu pengukuran dapat dipercaya atau diandalakan. Reliability menunjukkan konsistensi suatu alat ukur dalam mengukur suatu subyek yang sama. Uji reabilitas ini dilakukan dengan menggunakan software SPSS windows 18 dengan hasil sebagai berikut:

Tabel 5 Hasil Uji Reabilitas Data

\begin{tabular}{c|l|c|l}
\hline No & \multicolumn{1}{|c|}{ Keterangan } & Score & \multicolumn{1}{c}{ Status } \\
\hline A & Aspek Bahan & 0,7562 & Reabilitas tinggi \\
B & Aspek & 0,9156 & Reabilitas Sangat tinggi \\
C & Aspek finishing & 0,867 & Reabilitas Sangat tinggi \\
\hline
\end{tabular}

Hasil uji utnuk tingkat kepentingan menujukkan bahwa dimensi adjustability dengan nilai 0.9156, sedangkan untuk dimensi yang paling rendah adalah bahan dengan nilai 0,7562

\section{Analisis HOQ (House of Quality)}

Langkah penerapan QFD diawali dengan mengumpulkan suara konsumen (voice of customer). Data didapat dari beberapa referensi yang berkaitan dengan kualitas desain produk alat terapi stroke. Sehingga dari data ini biasa diketahui atributatribut apa saja yang disyaratkan atau yang diperhatikan oleh konsumen. Nilai tingkat 
kepentingan persyaratan konsumen diperoleh dari rata-rata persepsi responden terhadap dimensi kualitas produk. Hasil rata-rata tersebut menunjukkan bahwa urutan kualitas produk berdasarkan

tingkat kepentingannya adalah dimensi kualitas produk.

Dalam tahap ini suara konsumen ditransformasikan kedalam $\mathrm{CR}$ (customer requirement) yang dengan jelas menggambarkan apa yang akan dilakukan konsumen dengn produk tersebut, misalnya bagaimana produk akan digunakan. Hasil dari atribut ini dikelompokkan seperti pada tabel...persyaratan ini akan menempati sebelah kiri HOQ.

Segmentasi/Pengelompokan Customer Voice Pengelompokan customer voice ini dilakukanuntuk mempermudah dalam membuat Technical Requirement. Pengelompokan customer voice ini dibagi menjadi 5 kelompok berdasarkan Affinity Diagram.

Tabel 5.6 Hasil Segmentasi/Pengelompokan Customer Voice

\begin{tabular}{|c|c|c|}
\hline No & \multicolumn{2}{|c|}{ Keterangan } \\
\hline A & \multicolumn{2}{|l|}{ Aspek Bahan } \\
\hline 1 & \multicolumn{2}{|c|}{ Bahan terbuat dari material yang ringan namun kuat } \\
\hline 2 & \multicolumn{2}{|c|}{ Bahan untuk pedal dan pegangan tangan tidak keras } \\
\hline 3 & \multicolumn{2}{|c|}{ Alat tidak mudah bergeser pada saat digunakan } \\
\hline 4 & \multicolumn{2}{|l|}{ Bahan tidak mudah karat } \\
\hline B & \multicolumn{2}{|l|}{ Aspek adjustability } \\
\hline 1 & \multicolumn{2}{|c|}{ Alat dapat diatur/disesuaikan panjang pendeknya } \\
\hline 2 & \multicolumn{2}{|c|}{ Putaran engkolan dapat diatur (ringan -berat) } \\
\hline 3 & \multicolumn{2}{|c|}{ Putaran engkol dapat digunakan untuk tangan dan kaki } \\
\hline 4 & \multicolumn{2}{|c|}{$\begin{array}{l}\text { Pada penggunaan untuk tangan dapat diatur panjang } \\
\text { pendeknya jangkauan }\end{array}$} \\
\hline 5 & \multicolumn{2}{|c|}{ Alat dapat dilipat jika dan mudah dalam penyimpanan } \\
\hline 6 & \multicolumn{2}{|l|}{ Mudah dalam perakitan } \\
\hline C & \multicolumn{2}{|l|}{ Aspek finishing } \\
\hline 1 & \multicolumn{2}{|l|}{ Cat/pelapis tidak mudah luntur } \\
\hline 2 & \multicolumn{2}{|l|}{ Tidak mudah terkelupas } \\
\hline 3 & \multicolumn{2}{|l|}{ Warna menarik } \\
\hline $\begin{array}{l}\text { din } \\
\text { ntaa } \\
\text { cant } \\
\text { ters } \\
\text { Jang }\end{array}$ & $\begin{array}{l}\text { ni dibuat berdasarkan } \\
\text { inta oleh konsumen. } \\
\text { konsumen yang sudah } \\
\text { m pada tabel } 4.7 \text {, dari } \\
\text { ebut dapat di tentukan } \\
\text { harus dilakukan untuk }\end{array}$ & $\begin{array}{l}\text { memenuhi permintaan kebutuhan dari } \\
\text { konsumen tersebut. Technical response } \\
\text { jumlahnya tidak harus selalu sama dengan } \\
\text { jumlah customer voice, tetapi semua } \\
\text { kebutuhan dan keinginan konsumen dapat di } \\
\text { penuhi oleh respon yang dibuat. Berikut ini } \\
\text { technical response yang dibuat untuk } \\
\text { memenuhi customer voice }\end{array}$ \\
\hline
\end{tabular}

Tabel 7 Technical response

\begin{tabular}{c|l}
\hline No & \multicolumn{1}{|c}{ Technical Respone } \\
\hline 1 & sambunagn antar komponen dengan mur baut \\
2 & perubahan penggunaan tangan kekaki dengan cara sliding slot \\
3 & finishing dengan cat oven \\
4 & bahan darai pipa dengan tebal $0.8 \mathrm{~mm}$
\end{tabular}


\begin{tabular}{l|l}
5 & terdapat instruksi perakitan \\
6 & terdapat karet penahan pada bagian yang bersentuhan dengan lantai
\end{tabular}

Berdasarkan hasil pada HOQ diatas maka dapat dilihat bahwa nilai/bobot tertinggi yaitu

pada kemudahan dalam perakitan. Rangking Tabel 8 rangking bobot atribut QFD

\begin{tabular}{c|l|c}
\hline No & \multicolumn{1}{|c}{ Atribut } & Rangking \\
\hline 1 & Mudah dalam perakitan & 1 \\
2 & Pada penggunaan untuk tangan dapat diatur panjang & 2 \\
3 & pendeknya jangkauan & 3 \\
4 & Bahan terbuat dari material yang ringan namun kuat & 4 \\
5 & Cat/pelapis tidak mudah luntur & 5 \\
6 & Bahan tidak mudah karat & 6 \\
7 & Alat tidak mudah bergeser pada saat digunakan & 7 \\
8 & Alat dapat dilipat jika dan mudah dalam penyimpanan & 8 \\
9 & Putaran engkol dapat digunakan untuk tangan dan kaki & 9 \\
10 & Warna menarik & 10 \\
11 & Alat dapat diatur/disesuaikan panjang pendeknya & 11 \\
12 & Putaran engkolan dapat diatur (ringan -berat) & 13 \\
13 & Bahan untuk pedal dan pegangan tangan tidak keras & 12 \\
\hline
\end{tabular}

\section{Desain Alat}

Desain alat yang akan dikembangkan adalah seperti pada gambar 3 berikut

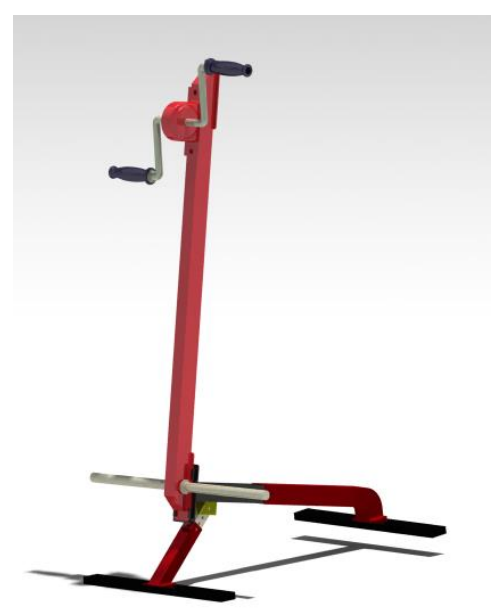

Gambar 3 konsep desain pengembangan alat terapi stroke

Berdasarkan data antropometri maka selanjutnya digunakan sebagai acuan untuk dalap mendesain untuk bagian pegangan tangan sesuai dengan dimensi antropometri yang telah diperoleh. Berikut adalah desain pegangan tangan seperti pada gambar 4

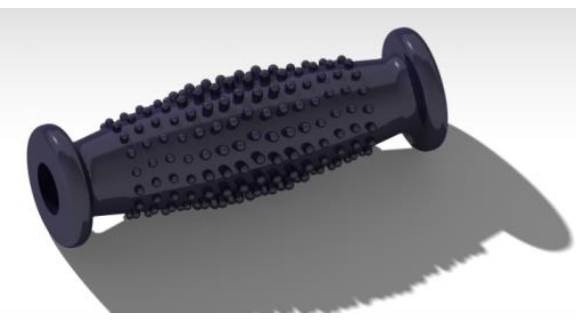

Gambar 4 desain handle

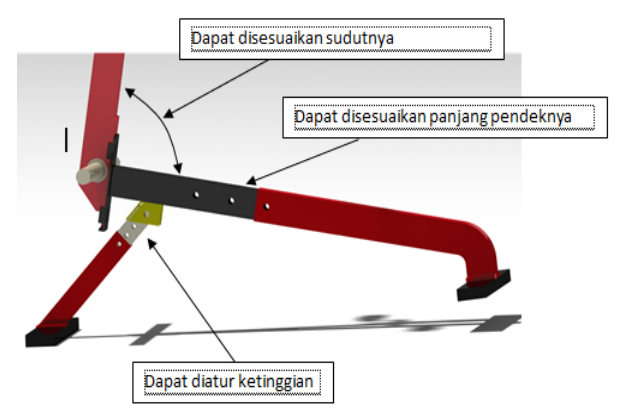

Gambar 5 desain adjustable alat terapi

\section{KESIMPULAN}

Hasil pengukuran data antropometri untuk persentil 5 adalah pada $\mathrm{Ptm}=73.26 \mathrm{~mm}$, Dgmak $=20.85 \mathrm{~mm}, \mathrm{Ttm}=16.98$, sedangkan untuk persentil 95 pada bagian $\mathrm{Ltm}=92.32$, Dgmin $=14.09$, Lkt=102.78 dan Tgkt=63.93. 
Uji reabilitas data menunjukkan bahwa aspek adjustability memiliki nilai tertinggi yaitu 0.9156, kemudian peringkat kedua aspek finishing dengan nilai 0.867 dan yang terakhir adalah aspek bahan dengan nilai 0.7562 . Berdasarkan keseluruhan atribut yang digunakan sebagai instrumentasi, yaitu sejumlah 13 atribut. Peringkat tertinggi adalah pada atribut mudah dalam perakitan

\section{REFERENSI}

Burdea, G., Popescu, V., Hentz, V., Colbert, K.(2000) "Virtual Reality-Based OrthopedicTelerehabilitation", IEEE Transactions on Rehabilitation Engineering, Vol. 8, No. 3,pp. 430-432.

Chandra, A,, Chandna, P, and Deswal, S.(2011). Analysis of Hand Anthropometric Dimensions of Male Industrial Workers of Haryana State, International Journal of Engineering (IJE), Vol, 5.

Dalgas, U., Stenager, E., IngemannHansen, T.(2008) Multiple sclerosis and physical exercise: recommendations for the application of resistance -, endurance- and combined-training. Multiple Sclerosis, 14 (1): 35-53.

Jezernik, S., Colombo, G., Morari, M., (2004). Automa tic gait-pattern adaptation algorithms for rehabilitation with a 4-DOF robotic orthosis. IEEE Transactions on Robotics and Automations, 20 (3): 574 $-582$.

Kwakkel, G., Wagenaar, R. C., Twisk, J. W., Lankhorst, G. J., da Muhaimin, Emir. (2015). Perancangan Kursi dengan Konsep Space-Saving dan Eco-Design pada Bangunan Apartemen UNS-F. Teknik Jur. Teknik Industri-I03100152015 